\title{
Supplementary material 2. Additional Figures and Tables
}

Supplementary Table 1. List of participant countries and number of respondents from each country.

\begin{tabular}{|l|l|}
\hline Country & $\begin{array}{l}\text { Number of } \\
\text { respondents }\end{array}$ \\
\hline United States & 38 \\
\hline Brazil & 24 \\
\hline India & 22 \\
\hline Italy & 22 \\
\hline Argentina & 17 \\
\hline Slovakia & 16 \\
\hline Germany & 13 \\
\hline Mexico & 10 \\
\hline Russia & 10 \\
\hline United Kingdom & 10 \\
\hline Canada & 9 \\
\hline Egypt & 8 \\
\hline Nigeria & 8 \\
\hline Spain & 8 \\
\hline Ukraine & 8 \\
\hline Romania & 7 \\
\hline Indonesia & 6 \\
\hline South Korea & 6 \\
\hline Peru & 5 \\
\hline Colombia & 2 \\
\hline Croatia & 2 \\
\hline France & 4 \\
\hline Japan & 4 \\
\hline Poland & 4 \\
\hline Bangladesh & 4 \\
\hline Chile & 3 \\
\hline China & 3 \\
\hline Greece & 3 \\
\hline Israel & 3 \\
\hline Philippines & 3 \\
\hline Serbia & 3 \\
\hline Thailand & 3 \\
\hline Turkey & 3 \\
\hline Australia & 3 \\
\hline Bulgaria & 2 \\
\hline Cuba & 2 \\
\hline Denmark & 2 \\
\hline Ethiopia & 2 \\
\hline Malaysia & 2 \\
\hline Mongolia & 2 \\
\hline Vietnam & 2 \\
\hline & 2 \\
\hline
\end{tabular}




\begin{tabular}{|l|l|}
\hline Algeria & 1 \\
\hline Armenia & 1 \\
\hline Austria & 1 \\
\hline Belgium & 1 \\
\hline Bosnia and Herzegovina & 1 \\
\hline Cameroon & 1 \\
\hline Democratic Republic of the Congo & 1 \\
\hline Equador & 1 \\
\hline Ghana & 1 \\
\hline Honduras & 1 \\
\hline Hungary & 1 \\
\hline Iraq & 1 \\
\hline Ireland & 1 \\
\hline Kuwait & 1 \\
\hline Kyrgyzstan & 1 \\
\hline Laos & 1 \\
\hline Mali & 1 \\
\hline Myanmar & 1 \\
\hline Netherlands & 1 \\
\hline Norway & 1 \\
\hline Pakistan & 1 \\
\hline Portugal & 1 \\
\hline Reunion & 1 \\
\hline Saudi Arabia & 1 \\
\hline Slovenia & 1 \\
\hline South Africa & 1 \\
\hline Sri Lanka & 1 \\
\hline Taiwan & 1 \\
\hline Tanzania & 1 \\
\hline United Arab Emirates & 1 \\
\hline Uruguay & 1 \\
\hline Not provided & 7 \\
\hline & \\
\hline & \\
\hline
\end{tabular}

Supplementary Table 2. Frequency and type of implemented scales for assessing tics and comorbidities in clinical practice. $\mathrm{N}$ refers to number of respondents. *only validated scales are listed.

\begin{tabular}{|c|c|c|}
\hline \multirow{11}{*}{$\begin{array}{l}\text { Domain } \\
\text { Tics }\end{array}$} & Scale & $\mathrm{N}$ \\
\hline & Yale Global Tic Severity Scale (YGTSS) & 123 \\
\hline & Tourette Syndrome - Global Clinical Impression & 70 \\
\hline & Modified Rush Video Protocol & 20 \\
\hline & Motor tic, Obsessions and compulsions, Vocal tic & 5 \\
\hline & Evaluation Survey (MOVES) & \\
\hline & Others & $5^{*}$ \\
\hline & Self report scale & \\
\hline & Skala für abnormale unwillkürliche Bewegungen & \\
\hline & Quality of life (QoL) & \\
\hline & Shapiro TS Severity Scale & \\
\hline
\end{tabular}




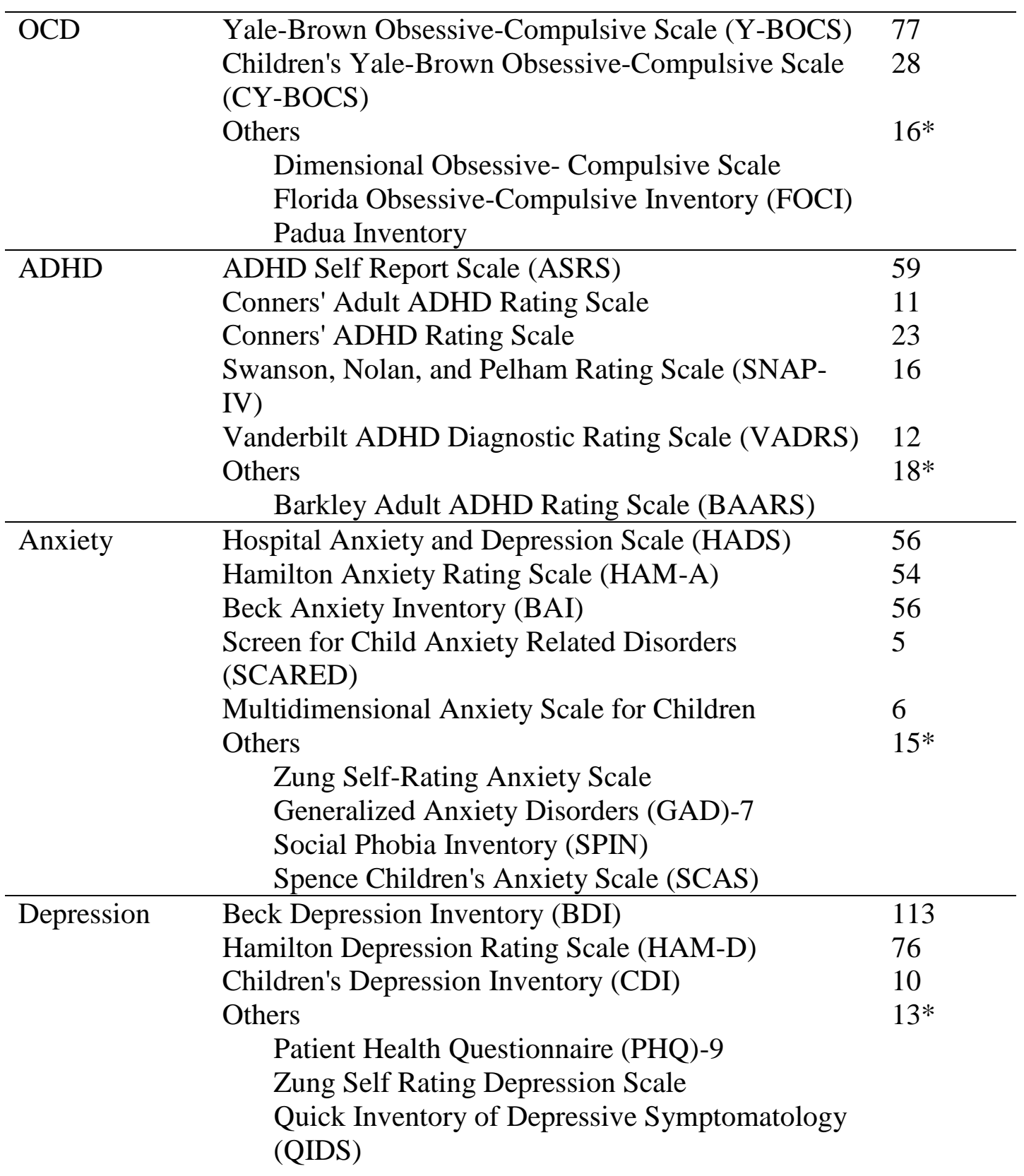

Supplementary Table 3. Ranked five most used medication in comparison between the Americas and Europe in adults.

\begin{tabular}{|l|l|l|l|}
\hline $\begin{array}{l}\text { Top adult medication } \\
\text { in the Americas }\end{array}$ & $\mathrm{N}^{*}$ & $\begin{array}{l}\text { Top adult medication in } \\
\text { Europe }\end{array}$ & $\mathrm{N}^{*}$ \\
\hline Clonidine & 53 & Aripiprazole & 48 \\
\hline Aripiprazole & 51 & Risperidone & 39 \\
\hline Risperidone & 51 & Quetiapine & 37 \\
\hline Tetrabenazine & 47 & Botulinum toxin & 36 \\
\hline Topiramate & 39 & Tetrabenazine & 33 \\
\hline
\end{tabular}

$*=$ Total number of responses for adults $=82$, for children/adolescents $=80$

Supplementary Table 4. Ranked five most used medication in comparison between the Americas and Europe in children $\left(5^{\text {th }}\right.$ place is shared in both the Americas and Europe).

\begin{tabular}{|l|l|l|l|}
\hline $\begin{array}{l}\text { Top child medication } \\
\text { in the Americas }\end{array}$ & $\mathrm{N}^{*}$ & Top child medication in & $\mathrm{N}^{*}$ \\
\hline
\end{tabular}




\begin{tabular}{|l|l|l|l|}
\hline & & Europe & \\
\hline Clonidine & 49 & Aripiprazole & 42 \\
\hline Risperidone & 48 & Clonidine & 34 \\
\hline Aripiprazole & 45 & Risperidone & 34 \\
\hline Topiramate & 36 & Tiapride & 25 \\
\hline Tetrabenazine & 31 & Topiramate & 22 \\
\hline Guanfacine & 31 & Haloperidol & 22 \\
\hline
\end{tabular}

$*=$ Total number of responses for adults $=70$, for children/adolescents $=67$

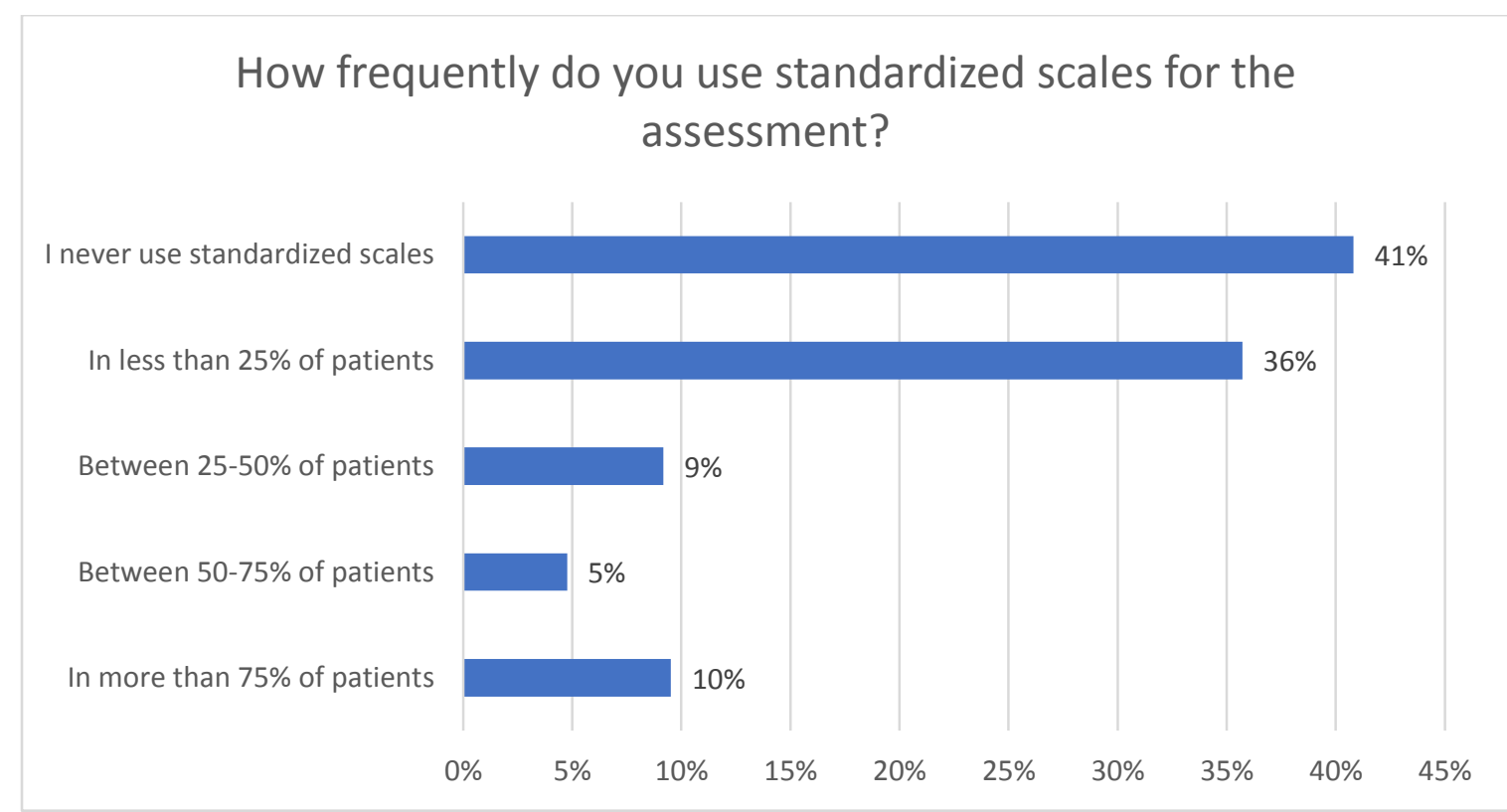

Supplementary Figure 1. Use of standardized tic severity scales in clinical practice. Total number of respondents: $n=294$.

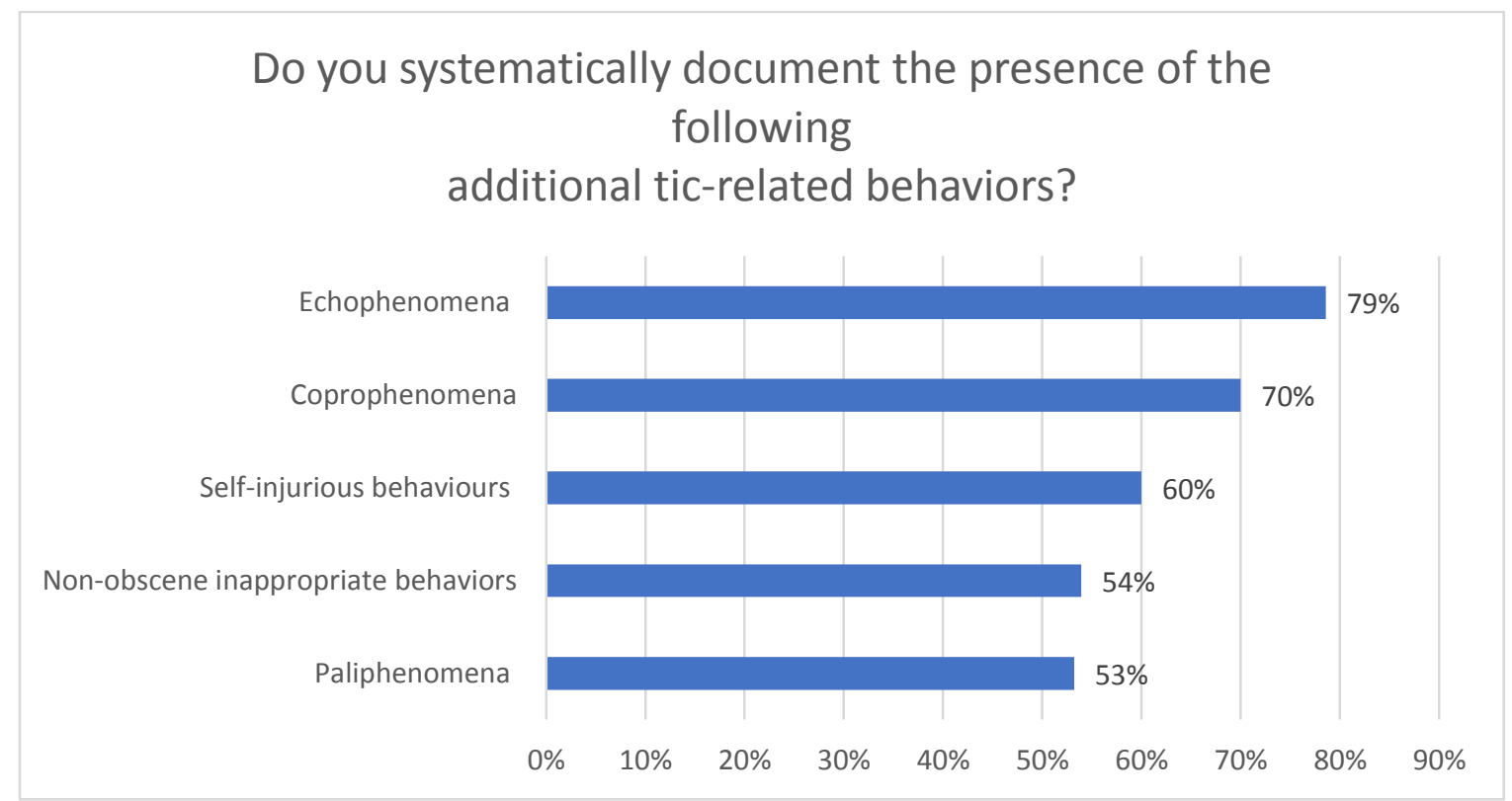


Supplementary Figure 2. Systematical documentation of the presence of additional ticrelated behaviors in clinical practice. Multiple choices per participant were possible. Total number of respondents: $\mathrm{n}=280$.

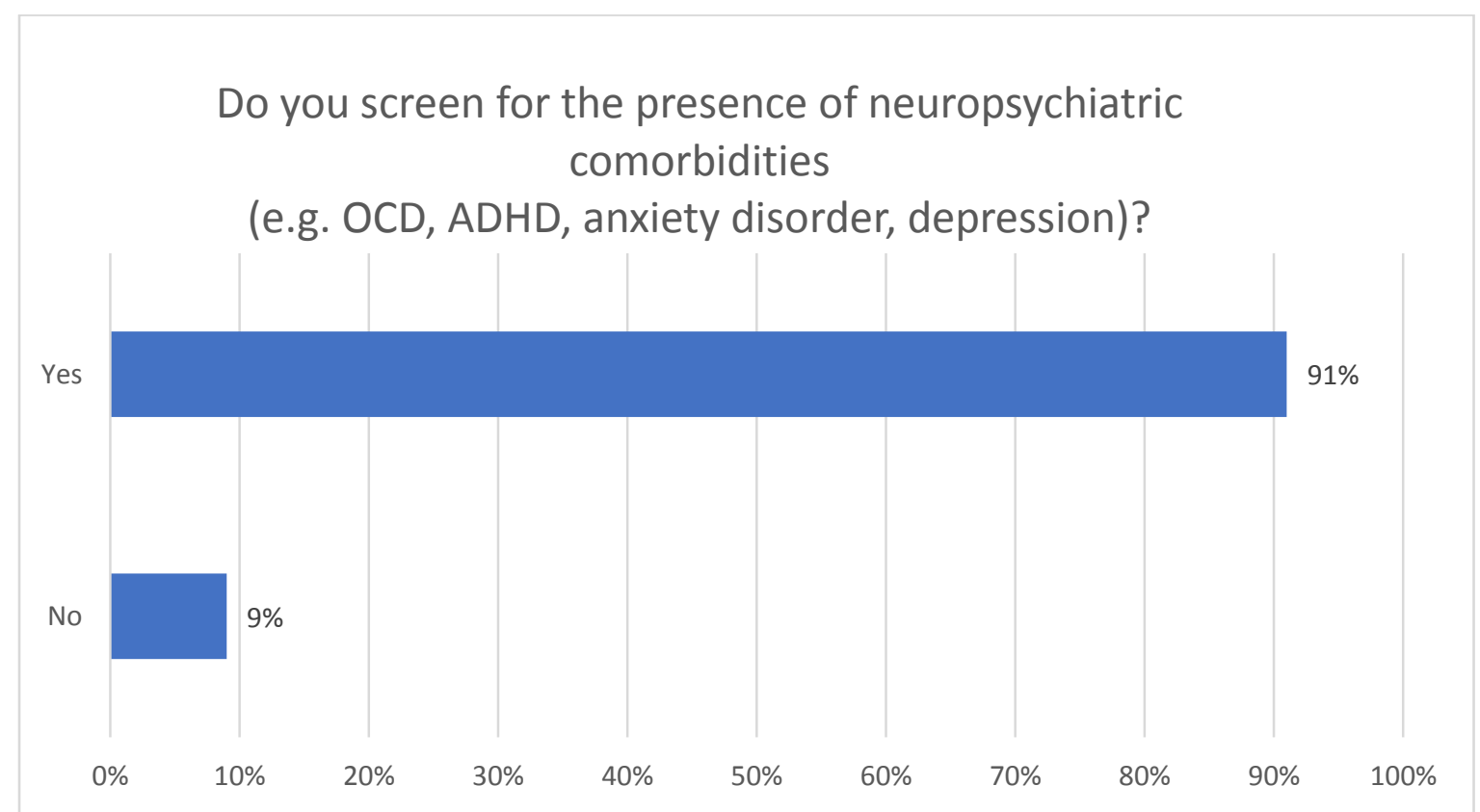

Supplementary Figure 3. Systematical screening of the presence of neuropsychiatric comorbidities in patients with tic disorders. Total number of respondents: $n=289$.

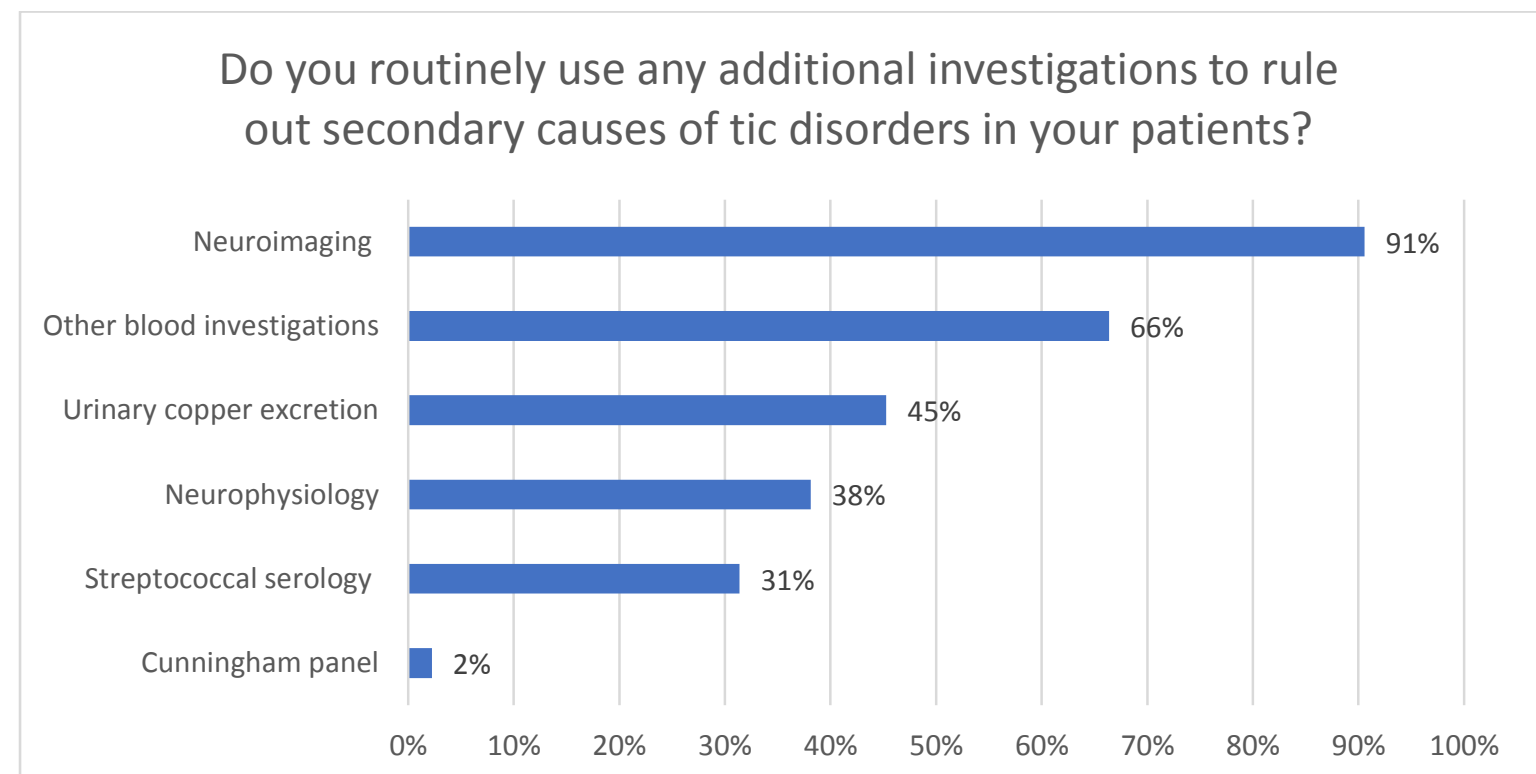

Supplementary Figure 4. Additional investigations for secondary tic disorders. Multiple choices per participant were possible. Total number of respondents: $n=223$. 


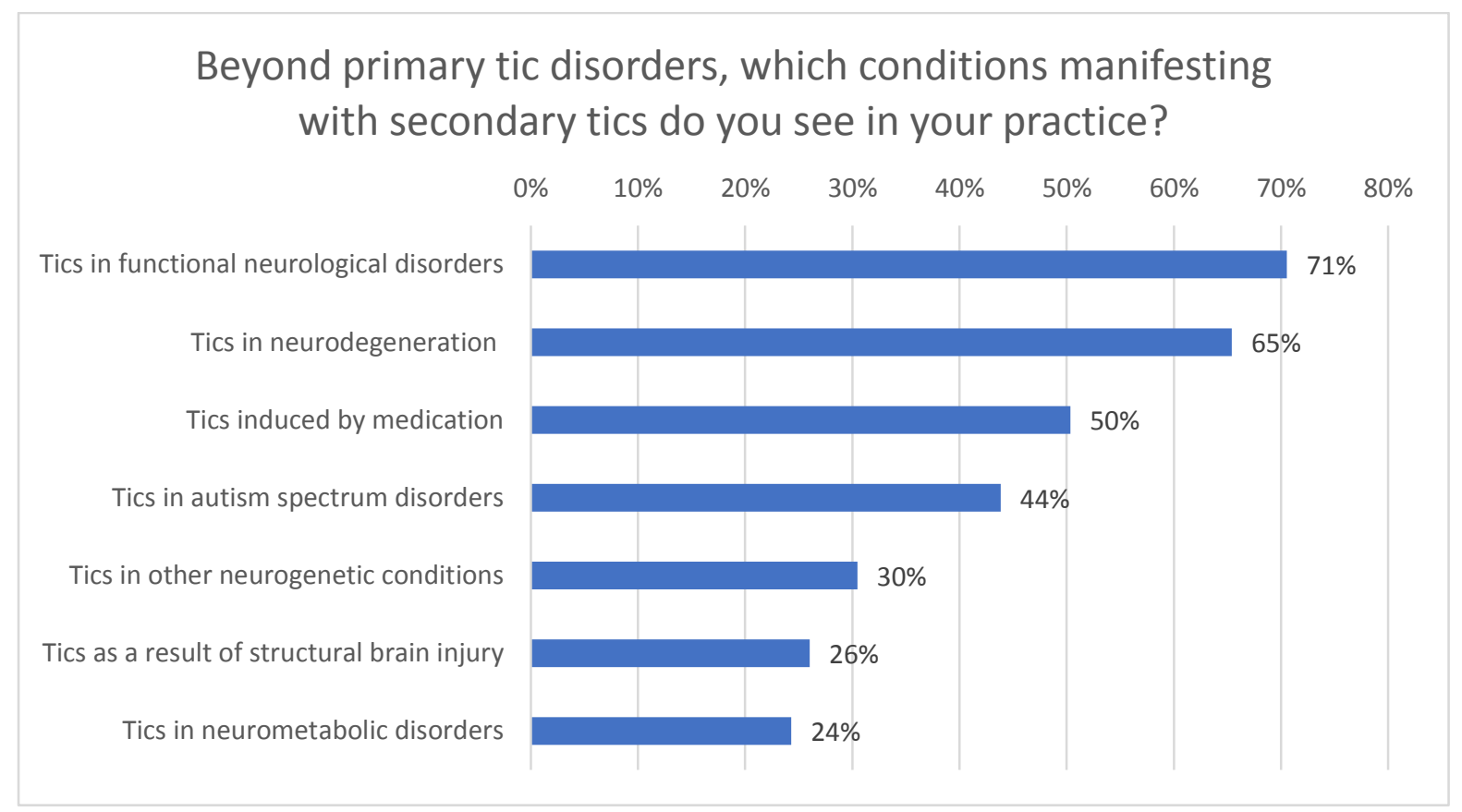

Supplementary Figure 5. List of tic etiologies beyond primary disorders. Multiple choices per participant were possible. Total number of respondents: $n=292$.

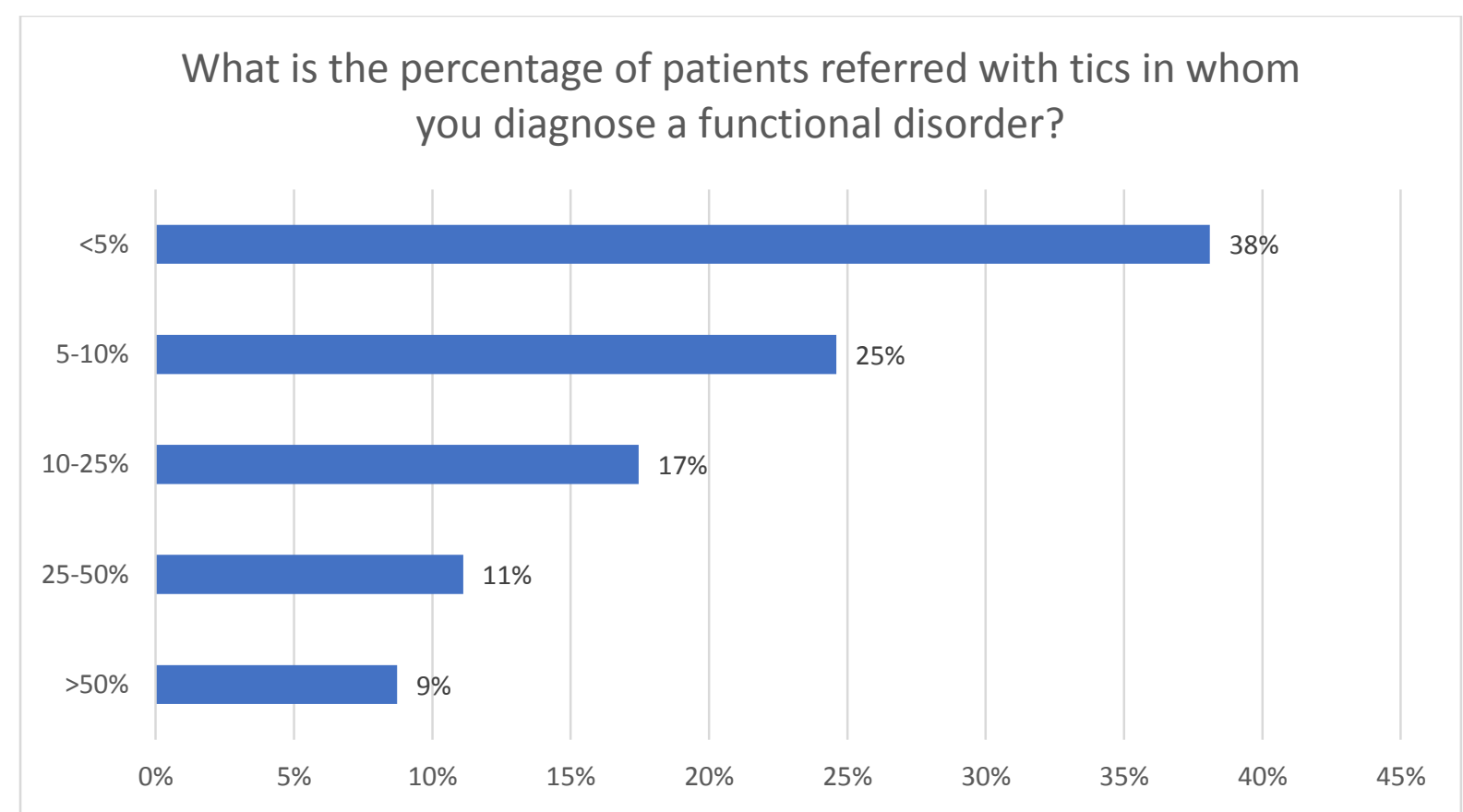

Supplementary Figure 6. Percentage of referred patients presenting with tic-like behaviors subsequently diagnosed with a functional tic-like disorder. Total number of respondents: $\mathrm{n}=$ 252. 


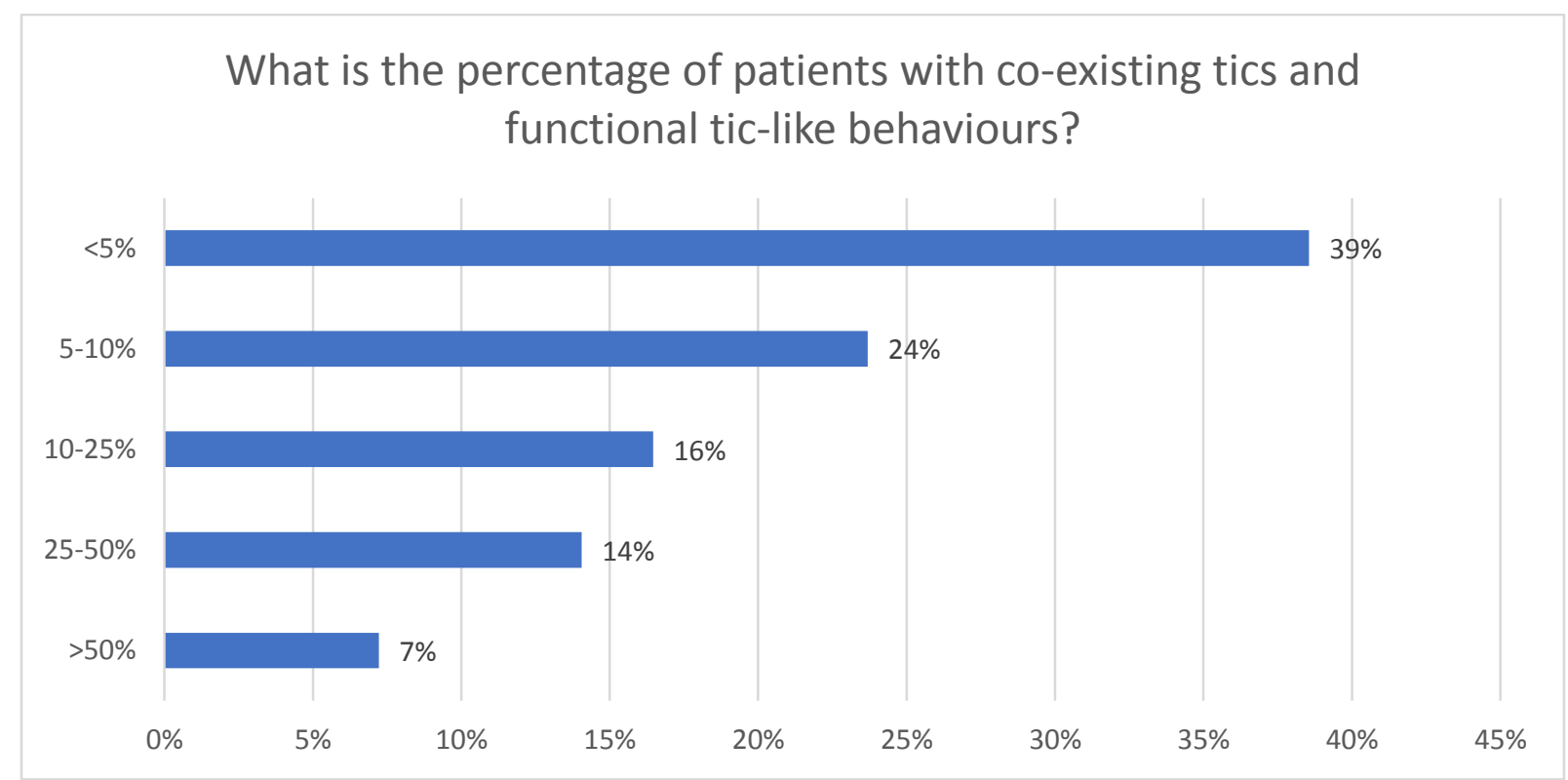

Supplementary Figure 7. Percentage of all patients with tic disorders with functional overlay. Total number of respondents: $n=249$.

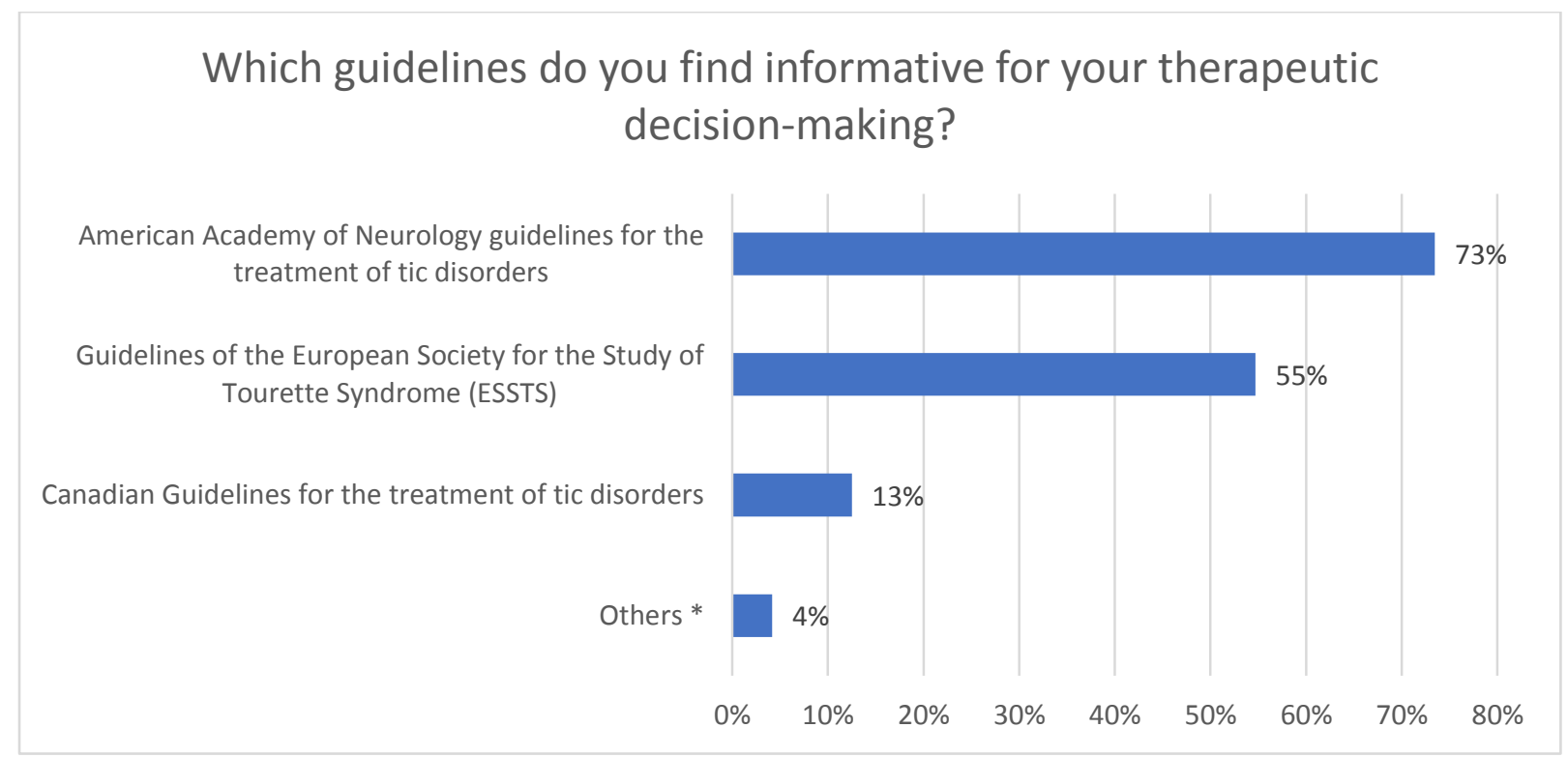

Supplementary Figure 8. Guidelines that were found informative for therapeutic decisionmaking. Total number of respondents: $n=192$. 


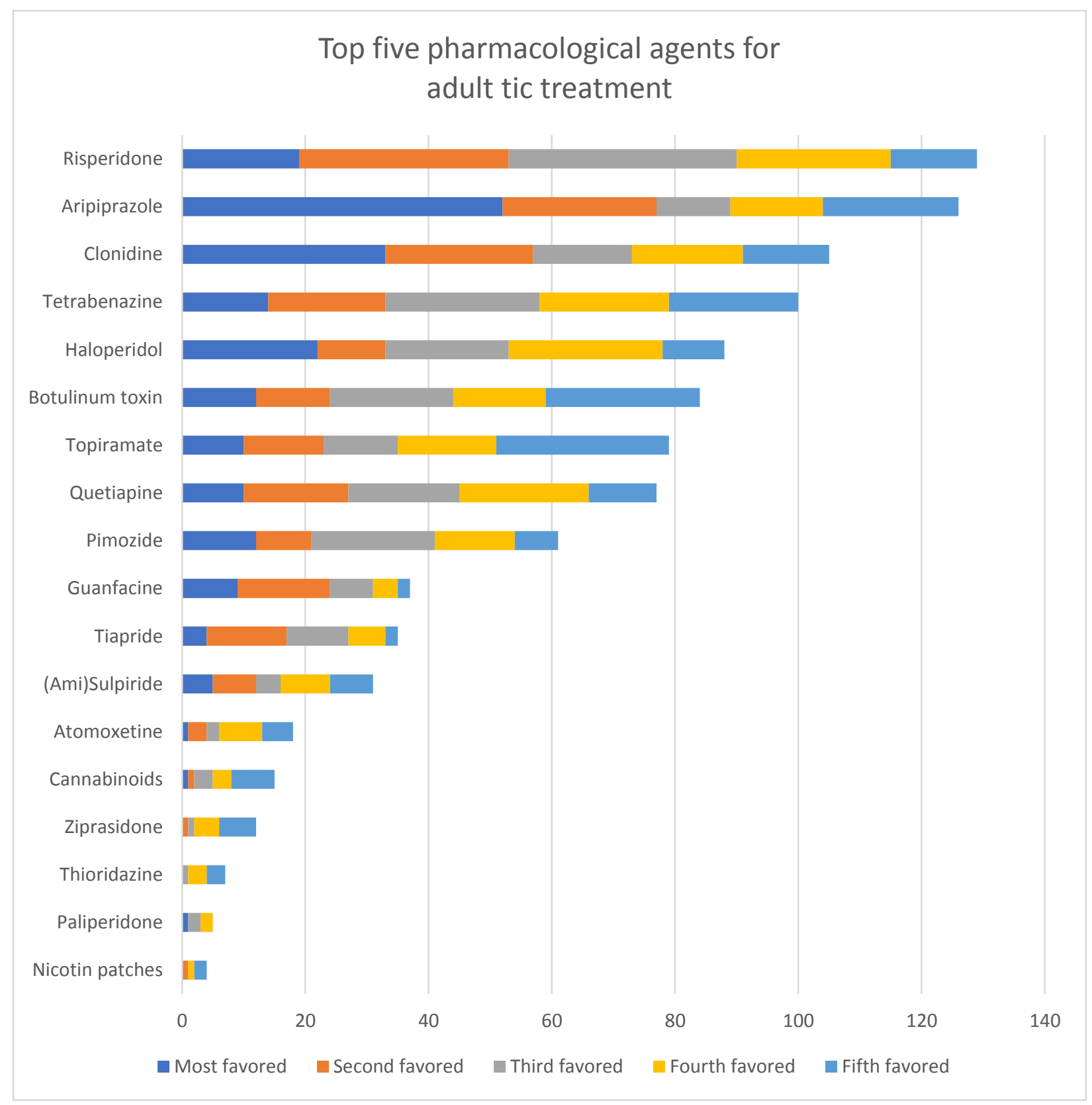

Supplementary Figure 9. Preferred top five pharmacological agents used for treating tics in adults. Total number of respondents: $n=220$. 


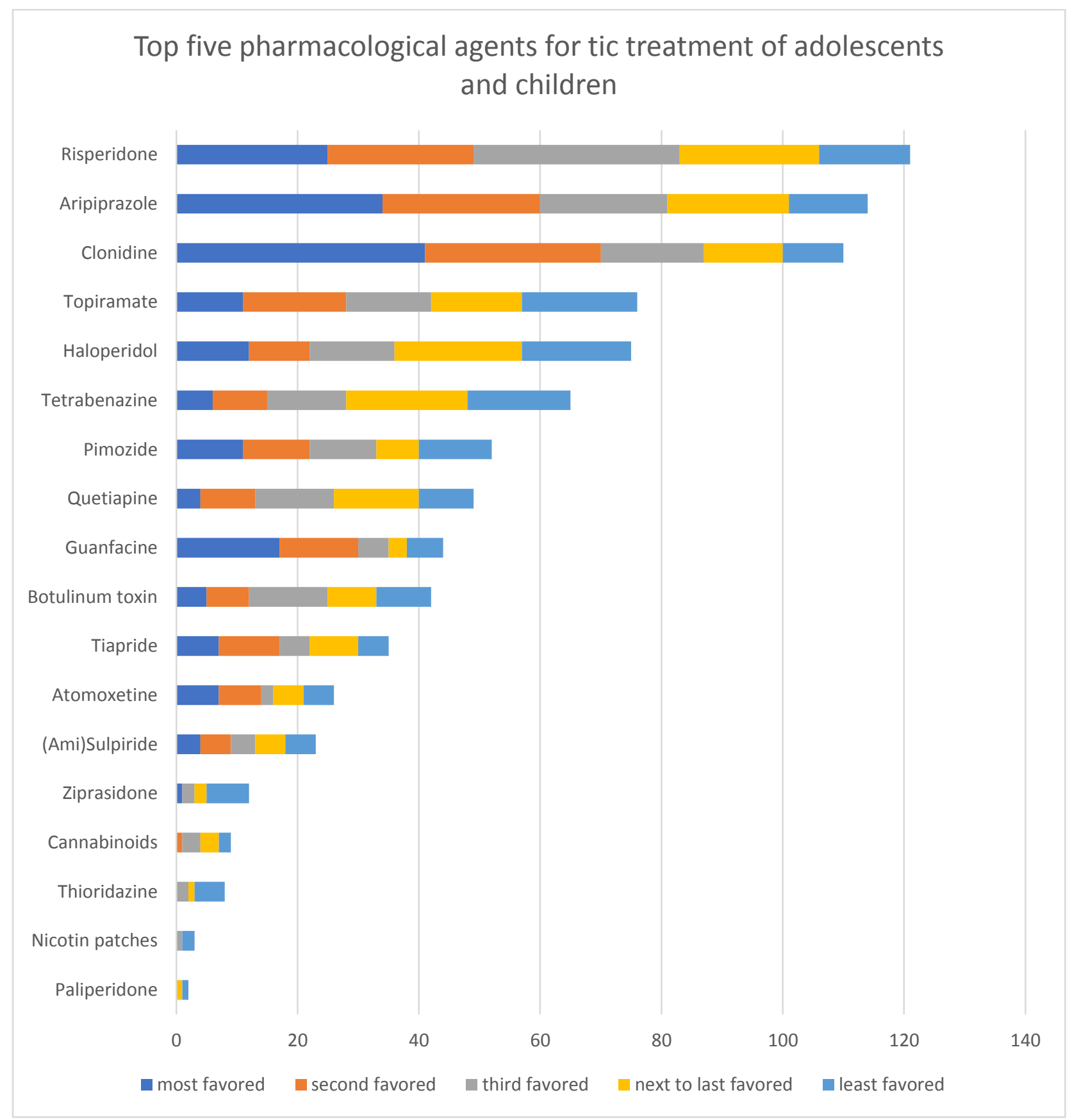

Supplementary Figure 10. The top five pharmacological agents used for treating tics in adolescents and children. Total number of respondents: $n=197$. 


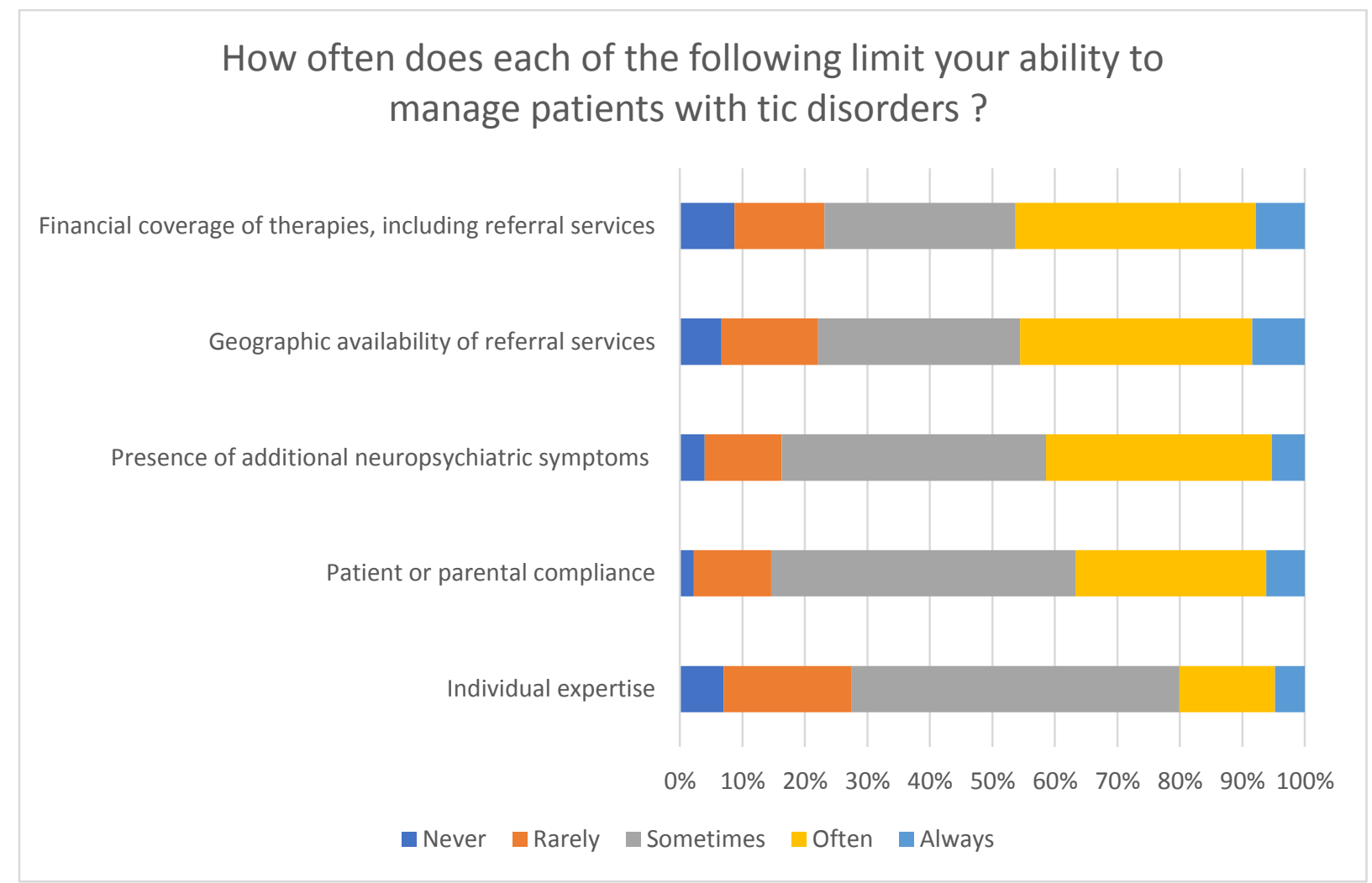

Supplementary Figure 11. Limiting factors to treatment success. Number of respondents: $n=$ 231.

\section{What are predictive factors for persistence of tics in adulthood?}

Number and severity of neuropsychiatric comorbidities

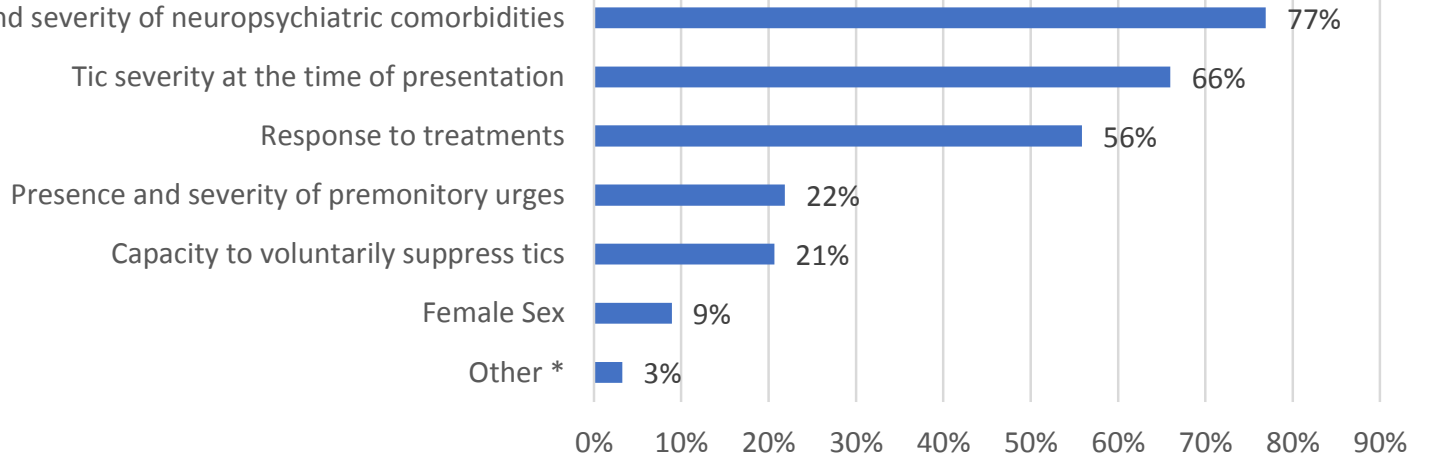

Supplementary Figure 12. Predictive factors suggested to influence prognosis of tic disorders. Multiple choices per participant were possible. Total number of respondents: $n=$ 247. 